\title{
Design and Analysis of off-board PV-Grid Adjustable Charger for Electric Vehicle Battery
}

\author{
Arshdeep Singh, Shimi Sudha Letha, Nikhil
}

\begin{abstract}
The electric vehicles (EVs) are emerging as general-purpose transportation, due to various shortcomings of traditional vehicles. The EVs will become ubiquitous only if its charging infrastructure is abundant and efficient. Typically, a module of Li-ion battery applied in EVs uses $4-6$ cells. These modules are connected in series-parallel combination to obtain the threshold power output. The power for the charging battery is delivered by the PV-grid topology. The solar and grid circuit uses a boost converter to create a dc bus. As the system uses boost converter for both $P V$ and grid circuit, therefore, charging profile can be adjusted by altering dc bus voltage. The battery used in different $E V s$ has a different configuration. The charger for EVs should be adjustable, as the traditional charger with fixed output will not charge the battery efficiently and results in reduced battery life. Therefore, a charger providing a fixed output will not serve the public demand. Hence, an adjustable charger has been proposed in this paper. The voltage and current profile of the charger can be adjusted according to the requirements of the $E V$ battery.
\end{abstract}

Keywords: Photovoltaic (PV) module, Maximum power point tracking, Li-ion Battery, Boost Converter, Battery Charger

\section{INTRODUCTION}

$\mathrm{T}$ he EVs are becoming popular as traditional vehicles are polluting the environment and fossil fuel reserves are on verge of extinction. In coming decades EVs would be a better choice of transportation. The traditional sources of energy are extinguishing due to which demand for renewable energy sources is increasing many folds. The solar energy is omnipresent however, power output is intermittent in nature due to its dependence on the irradiance and temperature. To obtain a regulated output at minimum losses the maximum power point tracking (MPPT) algorithm is applied to produce a dynamic duty ratio for the boost circuit. The PV-grid charging is more beneficial than a standalone PV system. As the standalone PV system requires a battery for storing charge. Therefore, battery maintenance has to be performed

Revised Manuscript Received on February 05, 2020.

* Correspondence Author

Arshdeep Singh*, Electrical Engineering, National Institute of Technical Teachers' Training and Research, Chandigarh, India. Email: arshdeep.elect@nitttrchd.ac.in

Shimi Sudha Letha, Electrical Engineering, National Institute of Technical Teachers' Training and Research, Chandigarh, India. Email: shimi.reji@gmail.com

Nikhil, Electrical Engineering, National Institute of Technical Teachers' Training and Research, Chandigarh, India. Email: nikhil.elect@nitttrchd.ac.in

(c) The Authors. Published by Blue Eyes Intelligence Engineering and Sciences Publication (BEIESP). This is an open access article under the CC BY-NC-ND license (http://creativecommons.org/licenses/by-nc-nd/4.0/) which is not required in the PV-grid system [1], [2]. In proposed model solar power is used as a primary source and grid supply is used as a secondary source. The Li-ion battery is used by most EVs manufacturing companies due to its high-power output with lesser weight compared to its peers. The Li-ion battery provides high specific energy (300 to $900 \mathrm{~kJ} / \mathrm{kg}$ ) depending upon its cathode material. The Li-ion battery has a major drawback despite its merits. Like lead-acid batteries, these cannot be charged from a regular supply. The charging of Li-ion battery has to be accomplished with a limited voltage and current supply. The charging via constant current and constant voltage gives the finest charging and longer retention of the charge. These batteries are not proficient in handling overcharging. Therefore charging has to be stopped immediately as soon as it is fully charged[3]. The characterisation of the Li-ion battery is determined by the material of cathode as shown in Table I. Usually, the cathode is a metal oxide of different elements. In general, the materials used by manufacturers for the cathode are Lithium Cobalt Oxide (LCO), Lithium Manganese Oxide (LMO), Lithium Iron Phosphate (LFP), Lithium Nickel Manganese Cobalt (NMC) and Lithium Nickel Cobalt Aluminum Oxide (NCA)[6]. The table shows the battery used by the various manufacturers in the EVs. This table verifies that different EVs have different battery configuration. Therefore, charging different batteries with a charger providing standard output will affect the state-of-health $(\mathrm{SoH})$ and eventually reduce its usable lifetime. Usually, LMO batteries are used by EV but nowadays NMC batteries are becoming popular. In this model LCO type of Li-ion battery is used as an EV battery prototype[7]. Table II shows a comparison between the LMO and LCO batteries. The LMO battery can provide higher current than the nominal capacity, therefore, they are preferred by most of the manufactures of EV. The LCO battery has higher specific energy thus to reduce the vehicle weight some manufacturers even use them for EV despite their higher cost[8]. The Li-ion battery cannot be charged with regular supply but requires a precise voltage and current profile from the charger. The battery SoH depends on the charging profile of the charger[10]. The charging profiles which are often applied are constant current (CC) charging and constant voltage (CV) charging. But there are some limitations in these charging techniques. In CC charging, a higher constant current is provided at a lower state of charge (SoC). In this technique overcharging may occur due to which battery temperature will rise to dangerous levels and results in gassing. Thus, applying the CC approach is absurd due to safety issues and regular charging will reduce the life of the battery. In CV charging, a small irregular current is provided for charging. In this approach, the battery is protected from overcharging however the charging time is increased. 


\section{Design and Analysis of off-board PV-Grid Adjustable Charger for Electric Vehicle Battery}

Thus, CC mode provides fast charging and CV mode charging is safer. Hence, both the approaches are combined to provide efficient charging to the battery. Therefore, CC mode is applied first for quick charging and then $\mathrm{CV}$ mode to protect battery from overcharging[11], [12].

Table-I: Li-ion Battery Cathode material for different EVs available in the Market [4], [5]

Table-II: Comparison between LCO and LMO Li-ion Battery[9]

\begin{tabular}{|c|c|c|c|}
\hline Cathode Material & $\begin{array}{c}\text { EVs } \\
\text { Developer-(Model) } \\
\end{array}$ & $\begin{array}{r}\text { Capacit } \\
\mathbf{y}(\mathbf{k W h}) \\
\end{array}$ & $\begin{array}{l}\text { Driving } \\
\text { Range } \\
\text { (miles) }\end{array}$ \\
\hline & Tesla-(S) & $60-100$ & $\begin{array}{c}334-50 \\
8 \\
\end{array}$ \\
\hline & Tesla-(X) & $60-100$ & $\begin{array}{c}334-50 \\
8 \\
\end{array}$ \\
\hline $\begin{array}{l}\text { Lithium Nickel Cobalt } \\
\text { Aluminum Oxide (NCA) }\end{array}$ & $\begin{array}{c}\text { Mercedes-(B-Class } \\
\text { Electric) }\end{array}$ & 28 & 137 \\
\hline \multirow[b]{2}{*}{$\begin{array}{l}\text { Lithium Cobalt Oxide } \\
\text { (LCO) }\end{array}$} & Tesla-(Roadster) & 56 & 245 \\
\hline & $\begin{array}{c}\text { Daimler Benz - } \\
\text { (Smart EQ) }\end{array}$ & 16.5 & 84 \\
\hline \multirow{4}{*}{$\begin{array}{l}\text { Lithium Manganese Oxide } \\
\text { (LMO) }\end{array}$} & Nissan-(Leaf EV) ${ }^{\mathrm{a}}$ & 24 & 105 \\
\hline & Think - $\underset{\text { a }}{\text { Think EV) }}$ & 23 & 99.4 \\
\hline & Mitsubishi-(i) $^{\text {a }}$ & 16 & 100 \\
\hline & Honda-(Fit EV) ${ }^{a}$ & 20 & 132 \\
\hline \multirow[b]{3}{*}{$\begin{array}{l}\text { Lithium Iron Phosphate } \\
\text { (LFP) }\end{array}$} & $\begin{array}{c}\text { Mitsubishi-(iMiEV) } \\
\text { a }\end{array}$ & 16 & 99.4 \\
\hline & BYD -(E6) & 57 & 249 \\
\hline & Chevrolet-(Spark) $^{\mathrm{a}}$ & 19 & 132 \\
\hline \multirow{8}{*}{$\begin{array}{c}\text { Lithium } \\
\text { (Nickel-Manganese-Cobal } \\
\text { t) Oxide (NMC) }\end{array}$} & Nissan-(New Leaf) & 24,30 & $\begin{array}{c}1,35,17 \\
2 \\
\end{array}$ \\
\hline & Hyundai- (Kona) & 39.2 & 345 \\
\hline & $\frac{B M W-(M i n i}{E)[i]}$ & 35 & 150 \\
\hline & BMW-(i3) & 22,23 & $\begin{array}{c}1,29,18 \\
3 \\
\end{array}$ \\
\hline & $\begin{array}{l}\text { Volkswagen-(e-Gol } \\
\mathrm{f}) \\
\end{array}$ & $24,35.8$ & $\begin{array}{c}1,35,20 \\
0 \\
\end{array}$ \\
\hline & Fiat-(500e) & 24 & 140 \\
\hline & Kia-(Soul EV) & 27 & 145 \\
\hline & Ford-(Focus EV) & 35.5 & 160 \\
\hline
\end{tabular}

\begin{tabular}{|c|c|c|}
\hline Specifications & LCO (used in the model) & LMO \\
\hline Cycle Life & 500 & $500-1000$ \\
\hline & & \\
Specific Energy (Wh/kg) & 155 & $100-120$ \\
\hline & & \\
Specific Power (W/kg) & $1 \mathrm{C}$ & $10 \mathrm{C}-40 \mathrm{C}$ \\
\hline Safety & Poor & Average \\
\hline Cost & High & Low \\
\hline
\end{tabular}

Generally, different EVs have different battery configuration. The batteries with different rating should be charged with different terminal voltage and charging current[13], [14]. If the same voltage and current are provided to different batteries, then the usable lifetime of the battery is reduced. Consequently, the charger output should match with the battery configuration. However, off-board EV chargers developed are not adjustable i.e. proving same rated voltage and current to different configurations of batteries.

In recent research articles, the focus of authors is on improving the charging time and efficiency. Furthermore, the effect of charging a different variety of batteries with the same terminal voltage is not considered. In [15] Mussa et al. verify that charging a Li-ion battery with fast charging up to $80 \%$ of SoC will provide more longevity to the battery, than a normal charge up to $100 \%$ of SoC. The author's conclusion is pivotal, but the application of Li-ion battery is not defined. In [6] Hannan et al. discuss various type of battery utilised in EVs. The authors provide an in-depth review of different materials of cathode used in the battery and issues related to them. But charging profile of the battery is not shown, which is crucial to the selection of battery for EVs. In [11] Yin et al. discuss a fast charger using a pulse current charging profile. In [16] Khan and Choi designed a multi-stage constant current charger with higher charging efficiency compared to the conventional charger. Although the improvement in charging time is necessary to charge more EVs in less time, the application of the fast charger is still unclear. If proposed chargers are applied on different EVs with the same charging current and voltage, then it will deteriorate the battery performance in the long run.

Mostly, off-board chargers use grid supply. If EVs are charged in bulk in future, then the power quality will be deteriorated. Also, power is mostly generated by thermal power stations in India. Generating more power implies more burning of coal which contributes to environmental pollution. To address these issues novel adjustable charger has been proposed to charge the battery according to its characteristics. In this charger boost converters are applied in both the solar and grid circuits. Therefore, the terminal voltage and current can be adjusted according to the battery requirements by varying the duty ratio. A low-cost microcontroller board provides a PWM signal for the boost converter. The measurement of voltage and current is received by the microcontroller board for generating signals to energise the source shifting mechanism. There are two relays which are used in this experiment to shift the source of the charger and the stages of the charger circuit. Furthermore, the charger has variable resistors (RV) in both CC and CV stages thus terminal voltage and charging current are adjustable at the charger circuit. The control of the charging voltage and current is achieved by the adjustable voltage regulator. The charging stages are chosen according to the instantaneous battery terminal voltage.

This paper is organised into four sections. In section 2, the materials and methods are discussed. In section 3 , the complete charging circuit of the battery is discussed in detail with experimental results. Next, in section 4 the results are analysed. Finally, the conclusion of the proposed work is presented.

\section{MATERIALS AND METHODS}

In this experiment, an adjustable charger is designed to charge batteries with different parameters. 
An optimum SoH can be maintained by adjusting the charging voltage and current. The complete block diagram of the system is described briefly. Then the flowchart of the charging circuit is illustrated. Finally, the charger circuit is illustrated in this section.

The general block diagram of the EV charging station is shown in Fig 1. The power for charging is provided by the PV-grid topology. The PV charging is optimised by maximum power point tracking (MPPT) algorithm. A modified perturb and observe algorithm is applied using voltage and current sensors. The relay-I shifts the source from solar to the grid, whenever solar power is insufficient to provide charging current. The terminal voltage of the battery is sensed by the voltage sensor. The instantaneous terminal voltage values are monitored by the microcontroller. The microcontroller will generate the pulse to energise the relay II to shift the operation mode from CC to CV. The measurement of battery terminal voltage guides the operation of the relay-II circuit. The charging current is provided by the relay to the battery. The normal charging of the battery is started by the $\mathrm{CC}$ and after the battery reaches the threshold voltage CV mode is applied for charging.

The charging of a Li-ion battery requires two stages i.e. constant current and constant voltage. The constant current is provided for charging Li-ion battery until threshold potential is achieved across the terminals. After that, a constant voltage is provided for charging which will sustain the charge in the battery. The charging cycle of Li-ion battery with a maximum voltage of $25.2 \mathrm{~V}$ (six Li-ion cells in series) is described by the following stages:
Over-discharge stage: If the terminal voltage of the battery falls below $17 \mathrm{~V}$ then the battery is considered as over-discharged. The charging of such a battery can be achieved by $0.1 \mathrm{C}$ charging current.

- Constant Current (CC) stage: If the terminal voltage of a Li-ion battery is between $17-25.2 \mathrm{~V}$ then a CC stage is applicable for charging. In this charging stage, a constant current of value less than $1 \mathrm{C}$ is given to battery for charging.

- Constant Voltage (CV) stage: When the terminal voltage is $25.2 \mathrm{~V}$ then a limited voltage supply is provided for charging. As the internal resistance of the battery increases the charging current will be reduced accordingly. When the charge current value remains only 3 to $10 \%$ of rated current then the battery is fully charged[15]-[17].

The flow chart of the circuit shown in Fig 2 describes the operation of the charging circuit. To optimize the output of the solar circuit $\mathrm{P} \& \mathrm{O}$ algorithm is implemented. The algorithm is using $\delta$ as the perturbation step. The power output from grid circuit is also given to dc bus. If the battery is deeply discharged, then the charging should be proceeded by small charging current known as a trickle charge. After the terminal voltage obtains certain threshold value (i.e. 17V) then the charging is accomplished by the CC circuit. If the battery potential exceeds the maximum voltage or current less than $10 \%$ of $1 \mathrm{C}$, then the duty of boost converter is set to zero and charging operation is stopped.

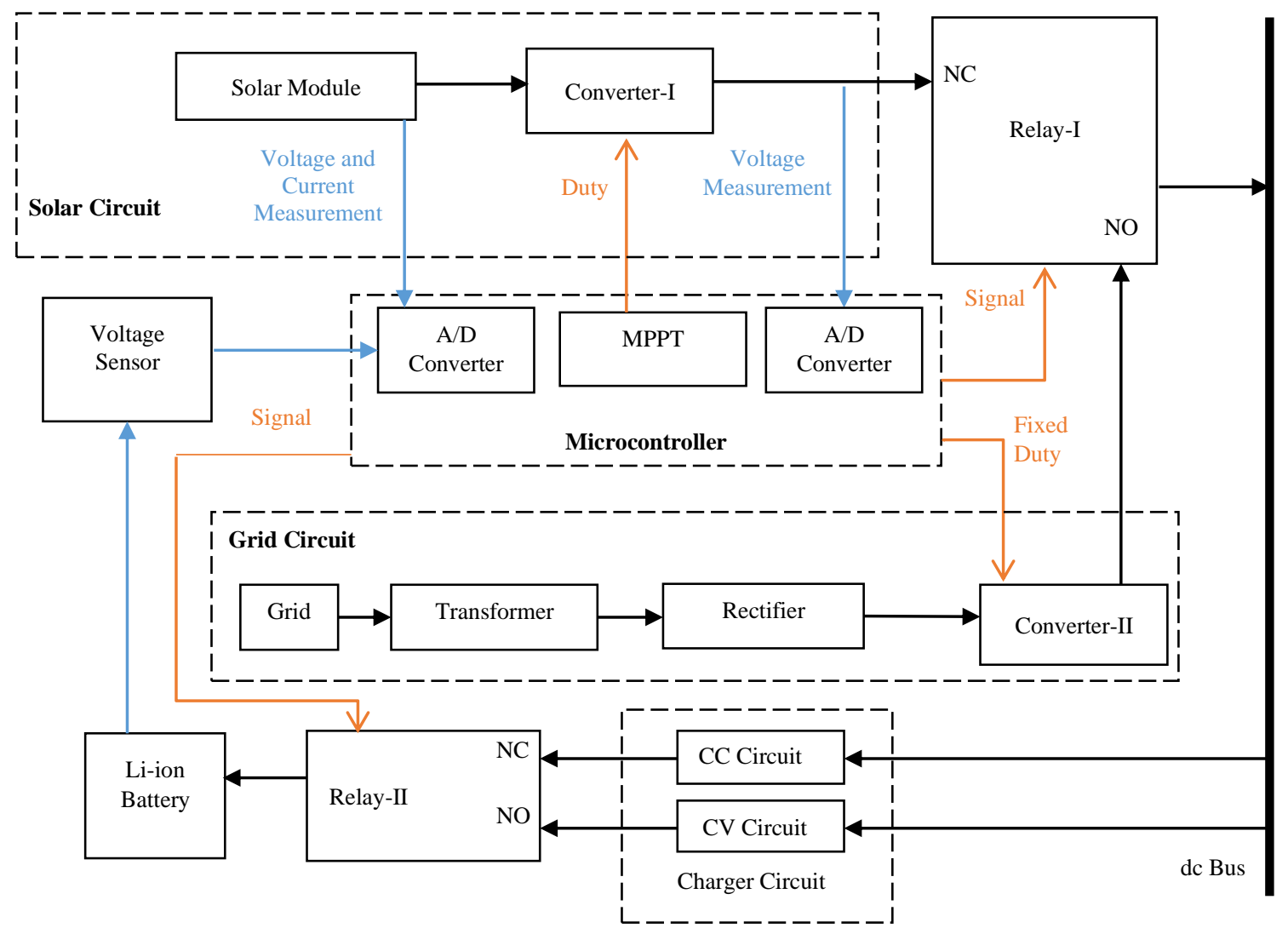

Fig.1. Block Diagram of the Adjustable PV-Gird Charger

Published By:

Blue Eyes Intelligence Engineering 1007 


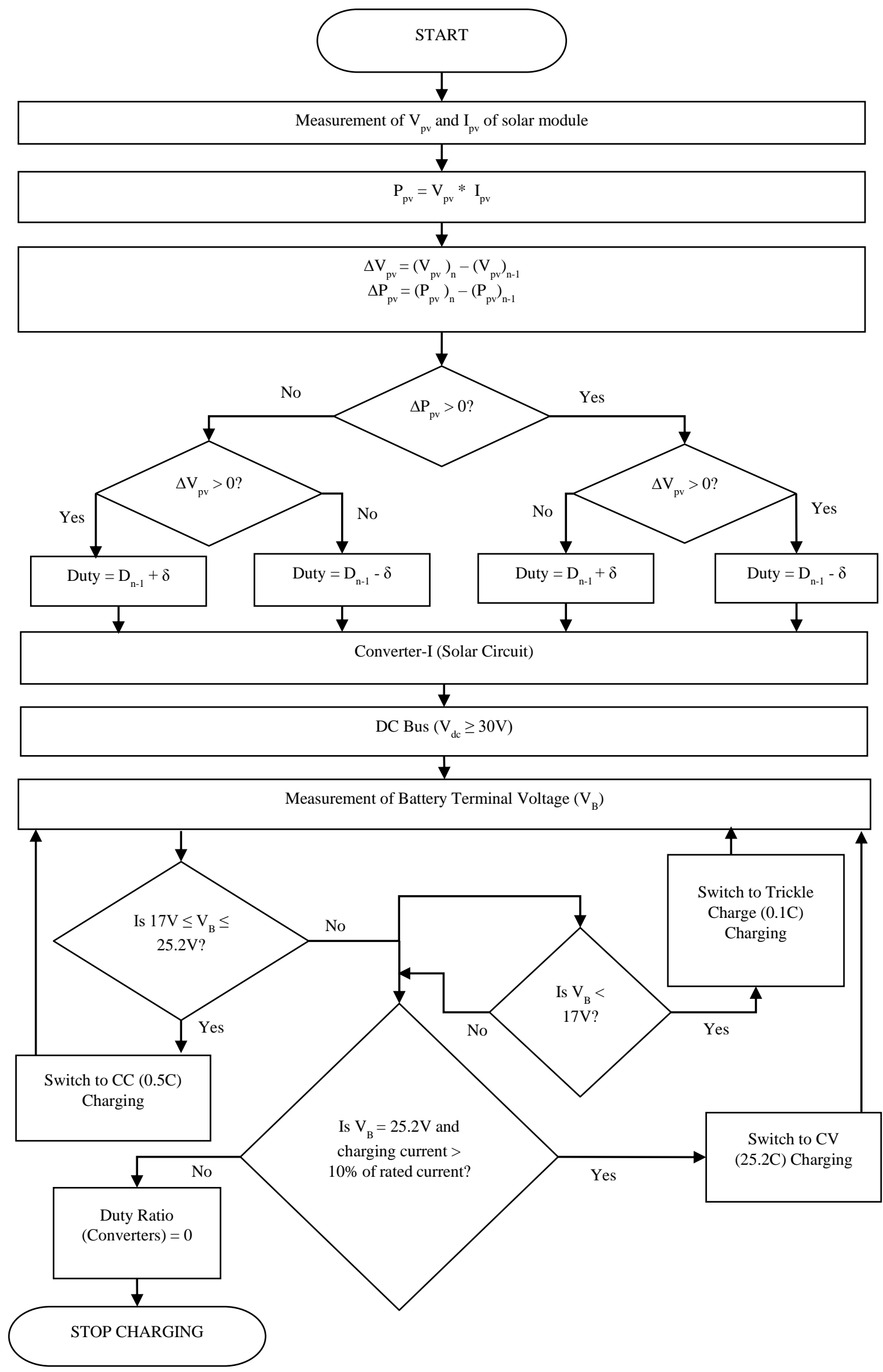

Fig.2. Flow Chart of the Adjustable CC-CV Charger for EV Battery 
The circuit diagram of the charger is shown in Fig 3. The dc bus will feed the charger circuit. The dc bus voltage and current are higher than the charging requirement, therefore limiting of current and voltage is necessary which is achieved by the adjustable voltage regulator (VR). The CC and CV stages are connected to each other in cascade. When the threshold voltage is achieved the CC circuit is disconnected and charging is done by the $\mathrm{CV}$ circuit. The output voltage of constant voltage $(\mathrm{CV})$,

$\mathrm{V}_{\mathrm{o}}=\mathrm{V}_{\text {ref }}\left(1+\mathrm{R}_{2} / \mathrm{R}_{\mathrm{a}}\right)+\left(\mathrm{I}_{\mathrm{adj}} \times \mathrm{R}_{2}\right)$ Where, $\mathrm{R}_{2}=\mathrm{R}_{\mathrm{b}}+\mathrm{RV}_{\mathrm{a}}$ (1)

The value of $\mathrm{Ra}$ is chosen independently. Therefore, in the above equation for a given output voltage $\left(V_{o}\right)$ values of $R_{b}$ and $\mathrm{RV}_{\mathrm{a}}$ can be calculated. Hence, by selecting the resistor value the voltage output is limited up to the required level for optimal charging.

The CC stage is connected to the output of the CV stage. The VR is connected to the CV stage, provides a constant current that can be adjusted with the variable resistor. The limiting current is given by,

$\mathrm{I}_{\text {limit }}=\mathrm{V}_{\text {ref }} / \mathrm{RV}_{\mathrm{b}}$

The output current limiting is achieved by selecting an appropriate value of $\mathrm{RV}_{\mathrm{b}}$ according to the charging requirements. The value of output voltage and current can be changed by simply varying the resistance values of the variable resistors. The specifications of the solar panel are given in Table III. The solar energy can give a maximum output voltage of 20V (approx.) but for charging the battery a $25.2 \mathrm{~V}$ nominal charging voltage is required. Therefore, a boost converter has to be designed for charging. This dc-dc converter act as an impedance matching device for the MPPT circuit.

Photovoltaic (PV) systems have low energy conversion efficiency due to their nonlinear current-voltage (I-V) and power-voltage (P-V) characteristic[18], [19]. The maximum output power fluctuates with the incident solar insolation and temperature. Moreover, the location of the MPP on the I-V curve could not be easily located. Therefore, it must be determined either through calculation models or by exploration algorithms. In addition, the process of tracking the MPP (maximum power point) should be very fast to deal with the fast changes in irradiance. The partial shading is responsible for the sudden change in irradiance and temperature of the PV panel. In partial shading, objects like planes, trees, clouds, or buildings cover the sun partially or wholly. Consequently, the MPP may change suddenly and rapidly. In such case power losses are high therefore MPPT provides better output power. In this model, modified P\&O is applied. In the algorithm, the dynamic perturbation step is implemented that depends on variation in temperature and irradiance. The algorithm is initially tested on MATLAB/SIMULINK platform and then implemented using a microcontroller[20], [21].

Table-III: Specification of Solar Module

\begin{tabular}{|l|l|}
\hline Parameter & Value \\
\hline Open circuit voltage (Voc) & $21.74 \mathrm{~V}$ \\
\hline Optimum operating voltage (Vmp) & $19.71 \mathrm{~V}$ \\
\hline Short circuit current (Isc) & $0.95 \mathrm{~A}$ \\
\hline Optimum operating current (Imp) & $0.90 \mathrm{~A}$ \\
\hline Power at STC (Pmax) & $17 \mathrm{~W}$ \\
\hline Temperature coefficient for power $\mathrm{W} /{ }^{\circ} \mathrm{C}$ & -0.043 \\
\hline
\end{tabular}

The solar power output is measured by a voltage sensor and a hall effect sensor. The values are used by the MPPT algorithm to produce a duty cycle according to changing environmental conditions. The dynamic duty cycle thus produced is given to boost converter. The voltage output of the boost converter is again measured. This value of output voltage will guide the triggering pulse to relay-I from microcontroller analog pin[22], [23]. The grid circuit for charging requires a step-down transformer. The charging requires dc supply; therefore, a rectifier is connected to the transformer. The rectifier produces unregulated supply; therefore, a dc-dc converter is applied to establish a regulated dc supply. The gate pulse for MOSFET is received from the microcontroller PWM pin. The dc-dc converter is connected to the relay circuit with reverse current protection diodes. The

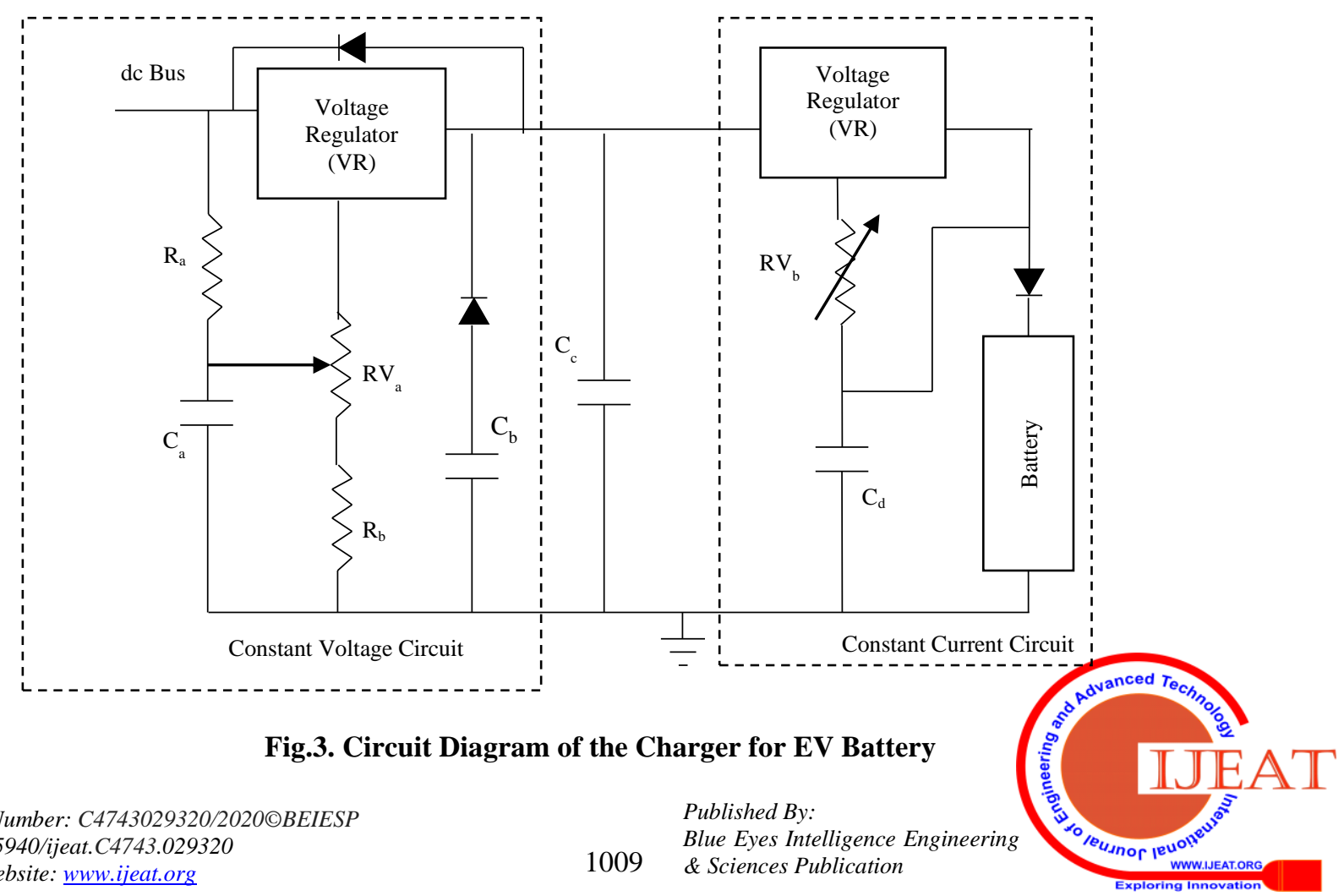




\section{Design and Analysis of off-board PV-Grid Adjustable Charger for Electric Vehicle Battery}

voltage values sensed from boost converter-I output is used by the relay-I to shift the source from PV to the grid. Whenever the PV power is not sufficient to charge the Li-ion battery the signal from the microcontroller will energise the relay coil to shift from PV circuit (NC) to grid circuit (NO). The output from the relay is connected to a common dc bus of the circuit[24], [25].

The dc bus is configured to provide higher voltage, thus limiting the voltage is essential for optimal charging. Thus, a $\mathrm{CC}$ and $\mathrm{CV}$ charging circuit has to be designed for optimum charging. The CC mode is frequently utilised therefore it is connected to the normally closed port of the relay. The battery terminal voltage is sensed and given to microcontroller. This value is used for generating signals for energising the relay switch to shift charging mode to $\mathrm{CV}$.

The supply indicator circuit will show the mode of supply for charging the EV battery. The circuit uses a transistor switch to shift indicating LEDs. The switching pulse is received from the microcontroller analog pin. Two different colour LEDs will indicate the source of charging power. Usually, in daylight, the charging will be accomplished by the PV module.

\section{RESULTS}

The battery charging and discharging is discussed in this section. The practical implementation circuit is shown in Fig 4. A prototype $\mathrm{EV}$ is used to discharge the battery. the EV battery. As the power output from a solar panel is intermittent therefore when power is inadequate grid system has to be utilised. Due to solar output dependence on the temperature and irradiance the power is varying with time. The output voltage given by the solar panel is $18 \mathrm{~V}$ at 530 $\mathrm{W} / \mathrm{m}^{2}$. The open-circuit voltage of the panel is $21.74 \mathrm{~V}$ as discussed earlier. The comparison of power output from boost converter with MPPT and without MPPT is shown in Fig 5 and Fig 6, at irradiance $194 \mathrm{~W} / \mathrm{m}^{2}$ and $530 \mathrm{~W} / \mathrm{m}^{2}$.

The nominal charging requires $500 \mathrm{~mA}$ at $25 \mathrm{~V}$ (i.e. $12.5 \mathrm{~W})$. At irradiance of $194 \mathrm{~W} / \mathrm{m}^{2}$ the power available is less than the required power and at $530 \mathrm{~W} / \mathrm{m}^{2}$, the power available is higher. If power available is less than the shifting mechanism will operate the grid circuit. Whereas, if power available is higher than voltage and current limiters used in the charger circuit will adjust charging parameters according to the requirement.

The charging of Li-ion battery (6 cells, 25.2V, 1000mAh) is done with the constant current constant voltage (CC-CV) charger. Initially, the terminal voltage is checked by the voltage sensor. If the voltage is above $17 \mathrm{~V}$ then the charging is initiated by the CC mode, otherwise, for deeply discharged battery a $0.1 \mathrm{C}$ current is applied for charging. After the battery terminal voltage sustains $25.2 \mathrm{~V}$ then a constant voltage mode is applied for charge retention. When the charging current is between $3-10 \%$ of rated current (i.e. 15 $50 \mathrm{~mA}$ ) Li-ion battery is considered to be completely charged. The battery after 3000 seconds (approx.) charging was found in normal temperature depicting a good SoH. The terminal voltage and charging current of the Li-ion battery

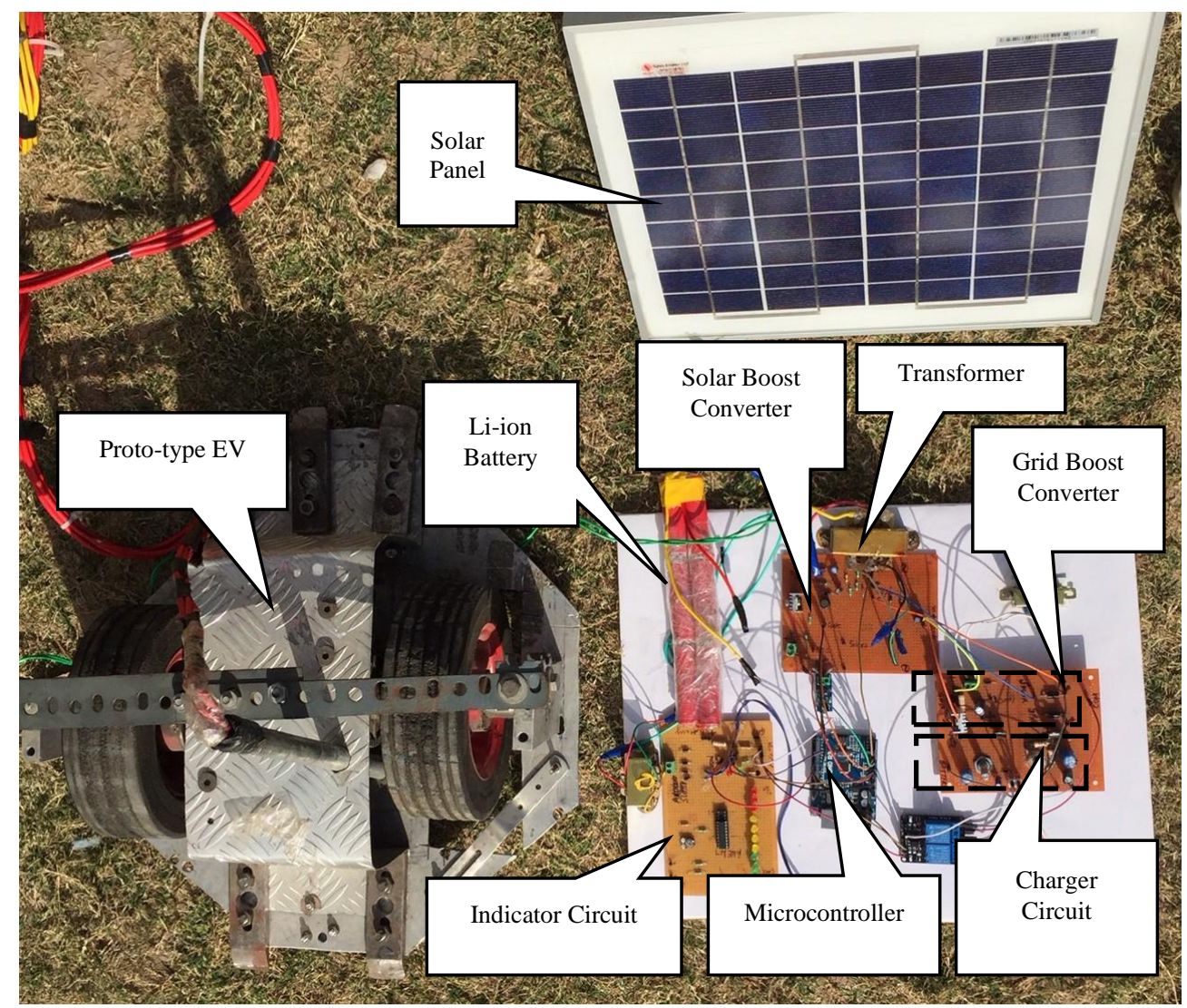

Fig.4. Hardware Implementation of the PV-Grid Charger with EV

The solar panel is chosen as the primary source to charge 


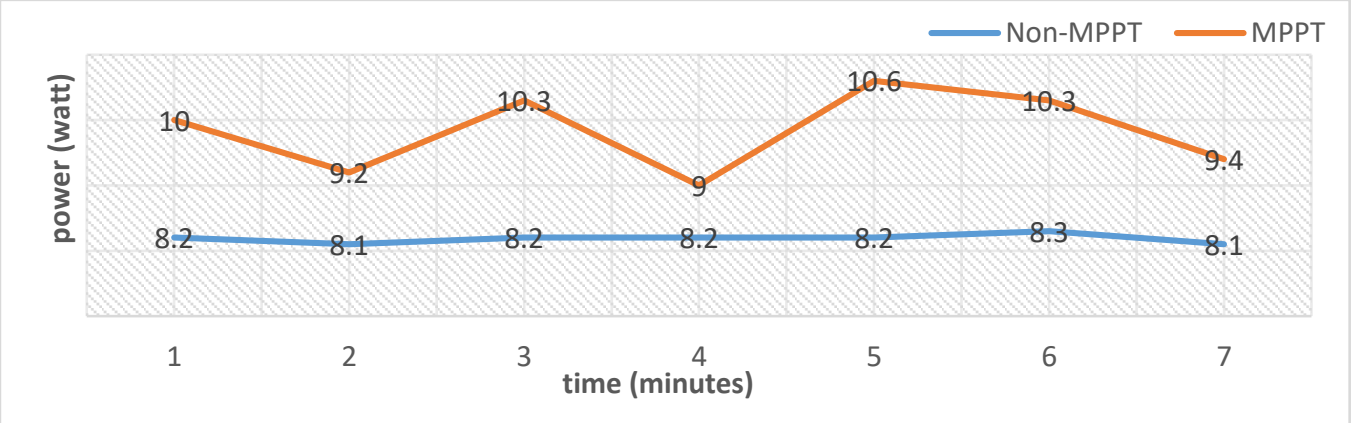

Fig.5. Power Output of Boost Converter-I at Irradiance $194 \mathrm{~W} / \mathrm{m}^{2}$

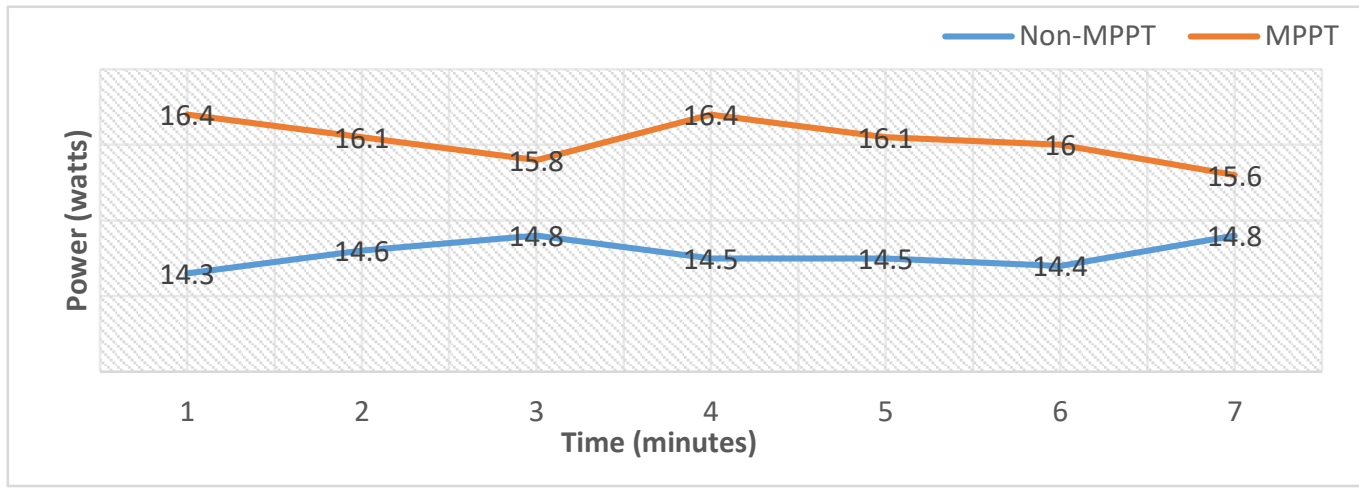

Fig.6. Power Output of Boost Converter-I at Irradiance $530 \mathrm{~W} / \mathrm{m}^{2}$

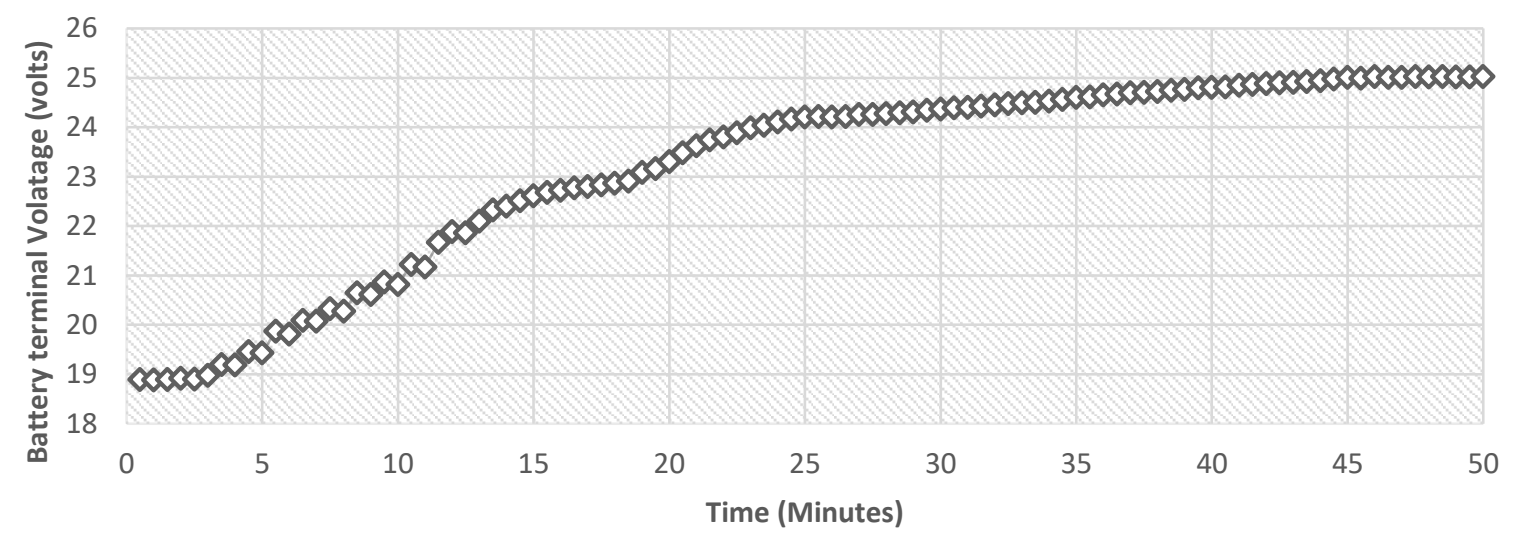

Fig.7. Terminal Voltage of Battery during Charging

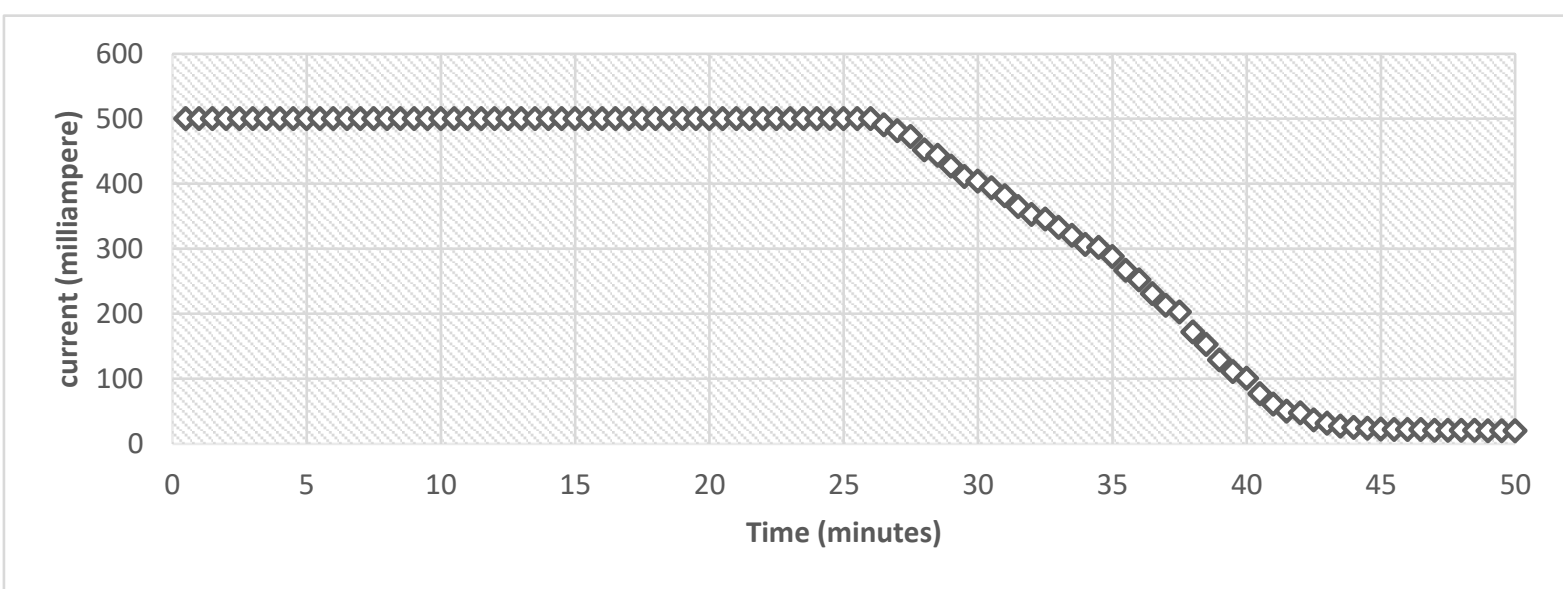

Fig.8. Charging Current given to Battery during Charging

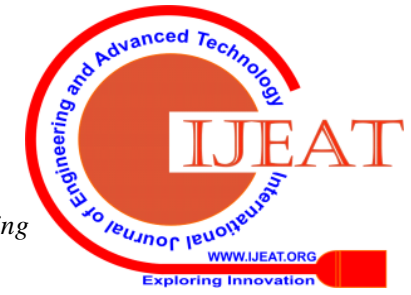




\section{Design and Analysis of off-board PV-Grid Adjustable Charger for Electric Vehicle Battery}

The same charger circuit is applied for charging a 4 cell Li-ion battery. The terminal voltage required for charging is $16.8 \mathrm{~V}$ but charging current required would be the same. The voltage output is adjusted for the CV stage. The charging of the battery is completed in 2450 seconds.

\section{DISCUSSION}

The battery is supposed to be used for an EV. The discharging of the battery is dependent on the load. In this prototype, the dc motor is used for traction purpose. The Li-ion battery parameters are listed in Table IV. The discharging of Li-ion is carried with a dc motor of EV. The range of the vehicle is estimated for a single discharge cycle.

Table-IV: Various Parameters of Li-ion Battery used in Model for Charging

\begin{tabular}{|l|l|}
\hline Battery Parameter & Value \\
\hline Nominal Current & $1.1 \mathrm{~A}(1 \mathrm{C})$ \\
\hline Nominal Voltage & $24 \mathrm{~V}$ \\
\hline Nominal Energy & $26.4 \mathrm{Wh}(1 \mathrm{C}$ discharging rate) \\
\hline Discharging Time (6 cells) & 12 Minutes (720 Sec) \\
\hline Discharging Time (4 cells) & 7 Minutes $(438 \mathrm{sec})$ \\
\hline
\end{tabular}

The motor angular velocity is 100RPM @ 25V (1.67RPS). The radius of the wheel is 0.2286 meter. Therefore, the linear velocity of the wheel is $0.381 \mathrm{~m} / \mathrm{sec}$. The discharge time of the battery is approx.720 Sec (From Table 4). It is observed that the driving range in a single discharge is 274.32 meter. Thus, calculation verifies that a 6-cell module can travel $274 \mathrm{~m}$ on a single charge. But manufacturers of EV use a higher number of modules in a series-parallel combination. Consequently, it would be mandatory to calculate the modules required to achieve a considerable distance for a single discharge cycle. A single Module of Li-ion consists of 6 cells in series $(25.2 \mathrm{~V} @ 1.1 \mathrm{Ah})$. The combination of two modules in parallel will provide 25.2V @ 2.2Ah (55.4Wh). If such pair of modules are connected in series, then it will provide 50.4V @ 2.2Ah (110.8Wh) which forms a single unit. If an EV utilizes 152 units then the energy delivered by the battery will be $16 \mathrm{kWh}$. Therefore, approximate distance covered with a $16 \mathrm{kWh}$ battery will be $166.25 \mathrm{~km}$. Thus, using such a battery combination (3,648 Li-ion cells) will drive EV for $166.25 \mathrm{~km}$.

\section{CONCLUSIONS}

An EV uses a Li-ion battery nowadays for providing power to dc motors for traction. In this model, a Li-ion battery having 6 cells in series with a nominal capacity of $1000 \mathrm{mAh}$ and the maximum terminal voltage of $25.2 \mathrm{~V}$ is used as a prototype for an EV battery. In general, EV battery has many Li-ion modules connected in series and parallel to provide required dc power. This prototype battery is similar to a single module which usually consists of 4 to 8 cells in series.

The charging of the battery by CC-CV charger provides longevity to the battery life. The EV charging station which is using PV-grid topology is developed on a small-scale application. The charger has double boost converters at solar and grid circuits. Therefore, the dc bus can be configured according to load parameters. The versatility of the charger is its unique feature. The charging station developed has charged a 6 cell Li-ion battery in 50 minutes. A 4-cell battery is also charged by the same charger with different charging profile. The 4 cell battery is completely charged in 2450 seconds.

\section{ACKNOWLEDGMENTS}

This study is supported by National Institute of Technical Teachers Training and Research (NITTTR), Chandigarh under Ministry of Human Resource Development, Government of India. I would also like to extend my gratitude to my research colleagues, faculty and staff at the electrical engineering department for their technical support.

\section{REFERENCES}

1. N. Sujitha and S. Krithiga, "RES based EV Battery Charging System: A Review," Renewable and Sustainable Energy Reviews, vol. 75, pp. 978-988, 2016.

2. J. Y. Yong, V. K. Ramachandaramurthy, K. M. Tan, and N. Mithulananthan, "A review on the state-of-the-art technologies of electric vehicle, its impacts and prospects," Renewable and Sustainable Energy Reviews, vol. 49, pp. 365-385, 2015.

3. A. Hoke, A. Brissette, K. Smith, A. Pratt, and D. Maksimovic, "Accounting for Lithium - Ion Battery Degradation in Electric Vehicle Charging Optimization," IEEE Journal of Emerging and Selected Topics in Power Electronics, vol. 6777, no. 3, pp. 691-700, 2014.

4. X. Chen, W. Shen, T. T. Vo, Z. Cao, and A. Kapoor, "An overview of lithium-ion batteries for electric vehicles," 10th International Power \& Energy Conference (IPEC), pp. 230-235, 2012.

5. G. E. Blomgren, "The development and future of lithium ion batteries," Journal of the Electrochemical Society, vol. 164, no. 1, pp A5019-A5025, 2017.

6. M. A. Hannan, M. M. Hoque, A. Hussain, Y. Yusof, and P. J. Ker, "State-of-the-Art and Energy Management System of Lithium-Ion Batteries in Electric Vehicle Applications: Issues and Recommendations," IEEE Access, SPECIAL SECTION ON ADVANCED ENERGY STORAGE TECHNOLOGIES AND THEIR APPLICATIONS, vol. 6, pp. 19362-19378, 2018.

7. M. A. Hannan, M. S. H. Lipu, A. Hussain, and A. Mohamed, “A Review of Lithium-ion Battery State of Charge Estimation and Management System in Electric Vehicle Applications: Challenges and Recommendations," Renewable and Sustainable Energy Reviews, vol. 78, pp. 834-854, 2017.

8. Z. Li, J. Huang, B. Y. Liaw, and J. Zhang, "On State-of-charge Determination for Lithium-ion Batteries," Journal of Power Sources, vol. 348, pp. 281-301, 2017.

9. S. Manzetti and F. Mariasiu, "Electric vehicle battery technologies From present state to future systems," Renewable and Sustainable Energy Reviews, vol. 51, pp. 1004-1012, 2015.

10. P. J. Liu and C. H. Yen, "A Fast-Charging Switching-Based Charger With Adaptive Hybrid Duty Cycle Control for Multiple Batteries," IEEE Transactions on Power Electronics, vol. 32, no. 3, pp. 1975-1983, 2017.

11. M. Di Yin, J. Cho, and D. Park, "Pulse-based fast battery IoT charger using dynamic frequency and duty control techniques based on multi-sensing of polarization curve," Energies, vol. 9, no. 3, 2016.

12. M. Restrepo, J. Morris, M. Kazerani, and C. Canizares, "Modeling and Testing of a Bidirectional Smart Charger for Distribution System EV Integration," IEEE Transactions on Smart Grid, vol. 3053, pp. 1-1, 2018.

13. K. Chung, S. K. Hong, and O. K. Kwon, "A fast and compact charger for an Li-Ion battery using successive built-in resistance detection," IEEE Transactions on Circuits and Systems II: Express Briefs, vol. 64, no. 2, pp. 161-165, 2017.

14. D. Zhang, H. Lin, Q. Zhang, S. Kang, and Z. Lu, "Analysis, Design, and Implementation of a Single-Stage Multipulse Flexible-Topology Thyristor Rectifier for Battery Charging in Electric Vehicles," IEEE Transactions on Energy Conversion, vol. 34, no. 1, pp. 47-57, 2019.

15. A. S. Mussa, M. Klett, M. Behm, G. Lindbergh, and R. W. Lindström, "Fast-charging to a Partial State of Charge in Lithium-ion Batteries: A Comparative Ageing Study," Journal of Energy Storage, vol. 13, pp. 325-333, 2017. 
16. A. B. Khan and W. Choi, "Optimal Charge Pattern for the High Performance Multi-Stage Constant Current Charge Method for the Li-ion Batteries," IEEE Transactions on Energy Conversion, vol. 8969, no. c, pp. 1-9, 2018.

17. M. M. Hoque, M. A. Hannan, A. Mohamed, and A. Ayob, "Battery charge equalization controller in electric vehicle applications: A review," Renewable and Sustainable Energy Reviews, vol. 75, no. November, pp. 1363-1385, 2017.

18. M. Di Yin, J. Youn, D. Park, and J. Cho, "Dynamic Frequency and Duty Cycle Control Method for Fast Pulse-Charging of Lithium Battery Based on Polarization Curve," 2015 Ninth International Conference on Frontier of Computer Science and Technology, pp. 40-45, 2015.

19. Y. E. Abu Eldahab, N. H. Saad, and A. Zekry, "Enhancing the Design of Battery Charging Controllers for Photovoltaic Systems," Renewable and Sustainable Energy Reviews, vol. 58, pp. 646-655, 2016.

20. H. Shareef, M. M. Islam, and A. Mohamed, "A review of the state-of-the-art charging technologies, placement methodologies, and impacts of electric vehicles," Renewable and Sustainable Energy Reviews, vol. 64, pp. 403-420, 2016.

21. A. R. Bhatti, Z. Salam, M. J. B. A. Aziz, K. P. Yee, and R. H. Ashique, "Electric Vehicles Charging using Photovoltaic: Status and Technological Review," Renewable and Sustainable Energy Reviews, vol. 54, pp. 34-47, 2016.

22. A. Mohapatra, B. Nayak, P. Das, and K. B. Mohanty, "A review on MPPT techniques of PV system under partial shading condition," Renewable and Sustainable Energy Reviews, vol. 80, no. February, pp. 854-867, 2017.

23. R. H. Julio Cesar Dias, "A Solar-Powered VRLA Battery Charge Controller using a DC-DC Ćuk Converter for a Telemetry Station Power Supply," in Power Electronics Conference and 1st Southern Power Electronics Conference (COBEP/SPEC), Fortaleza, Brazil, 2015, pp. $1-5$

24. A. M. Noman, K. E. Addoweesh, and H. M. Mashaly, "Simulation and dSPACE Hardware Implementation of the MPPT Techniques using Buck Boost Converter," Canadian Conference on Electrical and Computer Engineering, May 5-8, 2014, Toronto, Ontario, Canada, pp. $1-8$.

25. A. Nayak, Biraja Prasad; Shaw, "Design of MPPT Controllers and PV cells Using MATLAB Simulink and Their Analysis," in International Conference on Nascent Technologies in the Engineering Field (ICNTE-2017), Navi Mumbai, India, 2017, pp. 1-6.

\section{AUTHORS PROFILE}

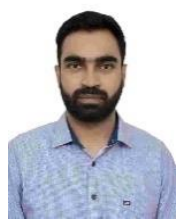

Arshdeep Singh, was born in Dabwali, Haryana State, India on August 31, 1992. He received the B.Eng. and M.Eng. in electrical and electronics from Panjab University Chandigarh, in 2014 and 2018, respectively. His employment experience includes UIET, Panjab University, Chandigarh, as faculty in Electrical and Electronics Engineering department. His research interests include power electronics, electrical vehicle charging and electrical drives.

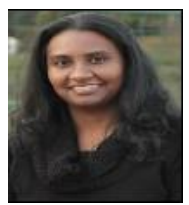

Dr. Shimi S.L, earned her Bachelor of Electrical and Electronics Engineering from J.J College of Engineering and Technology, Trichy, Tamil Nadu and Master of Power Electronics and Drives from Saranathan College of Engineering, Trichy, Tamil Nadu and PhD from PEC University of Technology, Chandigarh. Her areas of specialization are Power Electronics, Digital Electronics, ANN, Fuzzy, ANFIS etc. Mrs Shimi S.L is a Member of IEEE (USA), IE(India) and ASME(US).

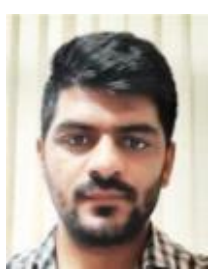

Nikhil, was born on 1st October 1992 in Sirsa, Haryana. He received his B.E. in Electrical Engineering from JMIT, Radaur, Haryana. He received his master's degree in Instrumentation and Control Engineering from NITTTR, Chandigarh. He is serving as Faculty in Electrical and Electronics Department of UIET. Panjab University, Chandigarh. His areas of interest include fault detection and diagnosis of induction motor, mathematical modelling, signal processing and optimization of parameters using bio-inspired algorithms. 